\title{
Fermentation du poisson en Afrique de l'Ouest et défis sociétaux pour une amélioration qualitative des produits (adjuevan, guedj et lanhouin): revue de la littérature
}

\author{
Moussou Fall ${ }^{1, *}$, Michel Bakar Diop ${ }^{1}$, Didier Montet $^{2,3}$, Amadou Seidou Maiga ${ }^{4}$ and Amadou Tidiane \\ Guiro ${ }^{5}$ \\ ${ }^{1}$ Université Gaston Berger, Unité de Formation et de Recherche des Sciences Agronomiques, de 1'Aquaculture et des Technologies \\ Alimentaires (UFR S2ATA), BP 234, Saint-Louis, Sénégal \\ 2 CIRAD, UMR QUALISUD, TA B-95/16, 73, rue J.-F. Breton, 34398 Montpellier cedex 5, France \\ ${ }^{3}$ QUALISUD, CIRAD, Montpellier SupAgro, Université d'Avignon, Université de la Réunion, Univ Montpellier, Montpellier, France \\ ${ }^{4}$ Université Gaston Berger, Unité de Formation et de Recherche des Sciences Appliquées et Technologies (UFR SAT), Section Physique \\ Appliquée, Saint-Louis, Sénégal \\ ${ }^{5}$ Université du Sine Saloum, Bureau de liaison de Dakar, Complexe Sicap Point E, Immeuble D-droite, 2 étage, avenue Cheikh Anta \\ Diop x canal 4,BP 45253, Dakar-Fann, Dakar, Sénégal
}

\begin{abstract}
Résumé - Le poisson est la principale source de protéines animales dans les zones côtières de l'Afrique de l'Ouest, notamment au Bénin, en Côte d'Ivoire et au Sénégal. Le problème de la conservation des produits halieutiques débarqués est un défi sociétal majeur dans ces pays du fait de l'insuffisance d'infrastructures industrielles. La transformation alimentaire traditionnelle contribue à la réduction des pertes post-capture. Divers produits transformés locaux comme l'adjuevan (Côte d'Ivoire), le lanhouin (Bénin) et le guedj (Sénégal), dont les procédés incluent le salage, la fermentation et le séchage, sont proposés aux consommateurs. Ils sont généralement utilisés comme condiments ou parfois comme sources majeures de protéines animales pour enrichir les apports nutritionnels des aliments à base de céréales locales. Les technologies traditionnelles employées pour ces produits sont peu coûteuses, du fait des équipements rudimentaires utilisés. La non-standardisation des techniques de production, notamment la fermentation, généralement spontanée, contribue à une qualité très fluctuante. Cette synthèse présente les différentes approches de fermentation conduisant aux divers produits ciblés, les caractéristiques physico-chimiques et microbiologiques de ces produits, les initiatives d'amélioration essentiellement basées sur le recours à des ferments et les défis sociétaux (renforcement de la recherche, formation des acteurs locaux, appui à la commercialisation) pour la croissance économique de ce secteur.
\end{abstract}

Mots clés : poisson / fermentation / procédé / commercialisation / qualité / Afrique de l'Ouest

\begin{abstract}
Fermentation of fish in West Africa and societal challenges for qualitative improvement of the products (adjuevan, guedj and lanhouin): A review. Fish is the main source of animal protein in the coastal areas of West Africa, including Benin, Côte d'Ivoire and Senegal. The problem of the conservation and storage of landed fish is a major societal challenge in these countries because of the lack of industrial infrastructures. Traditional food processing is then the only way for fish preservation and reduction of postcapture losses. Various local processed fish such as adjuevan (Côte d'Ivoire), lanhouin (Benin) and guedj (Senegal), whose processes include salting, fermentation and drying, are available to consumers. They are generally used as condiments or sometimes as major sources of animal protein to enrich the nutritional intake of local cereal-based foods. Traditional technologies are inexpensive because of the rudimentary equipment used. The non-standardization of production techniques including fermentation, usually spontaneous, contributes to a very fluctuating quality. This synthesis study highlights the different fermentation approaches leading to the various targeted products, the physico-chemical and microbiological
\end{abstract}

\footnotetext{
* Auteur de correspondance : moussou252000@yahoo.fr
} 
characteristics of these products, the initiatives of quality improvement mainly based on the use of starters as well as societal challenges (strengthening research, local actors training, marketing support) for economic growth.

Keywords: fish / fermentation / processing / marketing / quality / West Africa

\section{Introduction}

En Afrique de l'Ouest, la pêche et la transformation artisanale des captures contribuent significativement à l'autoemploi, à la rentrée de devises et aux stratégies pour atteindre la sécurité alimentaire et nutritionnelle. La capture totale annuelle de la pêche artisanale maritime dans la zone UEMOA (Union économique et monétaire Ouest Africaine), qui regroupe 8 États membres incluant le Sénégal, la Côte d'Ivoire et le Bénin, a été évaluée à 579639 t. Elle apparaît sensiblement supérieure à celle de la pêche continentale, qui était d'environ 300000 à $330000 \mathrm{t}$ en 2012. Cette différence entre les captures débarquées dans les deux types de pêche est due à la production maritime sénégalaise et dans une moindre mesure à celle de la Guinée Bissau. Le débarquement de la pêche artisanale maritime dans la zone UEMOA représente environ $2,1 \%$ du total des pêches artisanales maritimes mondiales (Enquête Cadre UEMOA, 2014).

La fermentation, une des principales techniques de transformation agroalimentaire, et parmi les plus anciennes, permet de limiter la détérioration des ressources agricoles, particulièrement en Afrique (Oyewole, 1997; Gram, 2003; Parkouda et al., 2009). Pratiquée de façon traditionnelle dans les pays côtiers d'Afrique de l'Ouest comme le Sénégal, la Côte d'Ivoire et le Bénin, elle consiste en une dégradation plus ou moins avancée des substances organiques sous l'action de micro-organismes et/ou d'enzymes endogènes, contrôlée ou non par le sel, en vue d'une stabilisation du produit et d'une modification de ses qualités organoleptiques (Gomna et Rana, 2007). La transformation du poisson par fermentation contribue également à la diversification des produits alimentaires locaux d'origine marine proposés aux consommateurs.

Les produits halieutiques fermentés locaux originaires d'Afrique de l'Ouest, commercialisés dans les marchés traditionnels en Afrique subsaharienne, sont principalement l'adjuevan de Côte d'Ivoire (Kouakou et al., 2013), le lanhouin du Bénin (Anihouvi et al., 2005) et le guedj du Sénégal (Fall et al., 2014). Ces produits transformés sont tous salés, fermentés et séchés. Ils sont très connus et consommés comme condiments du fait de leur saveur par la quasi-totalité des populations locales ou par les diasporas originaires d'Afrique de l'Ouest dans les pays développés (Essuman, 1992; Dossou-Yovo, 2002; Anihouvi et al., 2005 ; Diop et al., 2010; Kouakou et al., 2013 ; Fall et al., 2014). Dans les zones rurales non côtières et enclavées où la distribution du poisson frais est difficile, ils sont ajoutés dans les aliments à base de céréales pour renforcer leur qualité nutritionnelle.

Les recherches sur ces produits (adjuevan, lanhouin et guedj) ont montré que l'absence de standardisation des techniques de production était à l'origine de la variabilité de leurs qualités physico-chimiques, microbiologiques et sensorielles (Anihouvi et al., 2006; Dossou-Yovo et al., 2011; Anihouvi et al., 2012a; Koffi-Nevry et Koussémon, 2012 ; Kouakou et al., 2013 ; Fall et al., 2014 ; Anihouvi et al., 2015 ; Fall et al., 2017). Des études sur l'optimisation de la fermentation et du séchage sont développées depuis quelques décennies pour contribuer au renforcement de la productivité et à l'amélioration qualitative des produits finis, incluant une réduction de l'utilisation excessive du sel, base majeure du contrôle des micro-organismes indésirables dans les techniques traditionnelles (Diop et al., 2009a; Dossou-Yovo et al., 2011; Kouakou et al., 2012a; Kouakou et al., 2012b; Anihouvi et al., 2012b; Anihouvi et al., 2012c ; Diop et al., 2015; Diop et al., 2016).

Cet article présente une synthèse des études réalisées sur l'adjuevan, le guedj et le lanhouin entre 2005 et 2017. Il est axé sur la comparaison des procédés traditionnels de préparation, les caractéristiques physico-chimiques et microbiologiques des produits et les essais d'optimisation de la fermentation. Ce travail a permis d'identifier des défis complémentaires à relever pour promouvoir le développement de l'économie maritime au Sénégal, en Côte d'Ivoire et au Bénin.

\section{Production de la pêche artisanale maritime en Afrique de l'Ouest}

Parmi les pays ciblés, la production artisanale maritime annuelle la plus importante est celle du Sénégal, évaluée à $492226 \mathrm{t}$, tandis que celles de la Côte d'Ivoire et du Bénin sont respectivement $40091 \mathrm{t}$ et $11144 \mathrm{t}$ (Enquête Cadre UEMOA, 2014)

Au Sénégal, la production de guedj a été estimée à 4613 ten 2014 (DPM, 2014). Cette production a augmenté progressivement pour atteindre $5606 \mathrm{t}$ en 2016 (DPM, 2016). Au Bénin, selon Anihouvi et al. (2005), la production de lanhouin est évaluée à $3000 \mathrm{t} / \mathrm{an}$ tandis qu'en Côte d'Ivoire, celle de l'adjuevan se situe entre 3000 et 5000 t/an (Kouakou et al., 2013).

Les trois types de produits sont majoritairement élaborés à partir d'espèces marines et plus minoritairement à partir d'espèces d'eau douce, contrairement au plaa-som en Thailande pour lequel seules des espèces d'eau douce sont utilisées (Palludan-Müller et al., 2002a). La fabrication des trois types de produits utilise essentiellement des espèces comme Galeoides decadactylus, Chloroscombrus chysurus et Pseudotholithus senegalensis. L'espèce Galeoides decadactylus, ou faux capitaine, est utilisée pour les trois types de produits. Elle est la première utilisée et appréciée pour la production de guedj (Fall et al., 2014) et constitue la deuxième espèce utilisée pour le lanhouin (Anihouvi et al., 2005) et l'adjuevan (Kouakou et al., 2013). Du fait de leur haute qualité organoleptique, les espèces comme Chloroscombrus chysurus et Pseudotholithus senegalensis sont les plus utilisées respectivement pour l'adjuevan (Kouakou et al., 2013) et pour le lanhouin (Essuman, 1992; Dossou-Yovo, 2002; Anihouvi et al., 2005). Pseudotholithus brachygnatus est la deuxième espèce utilisée pour le guedj (Fall et al., 2014). 


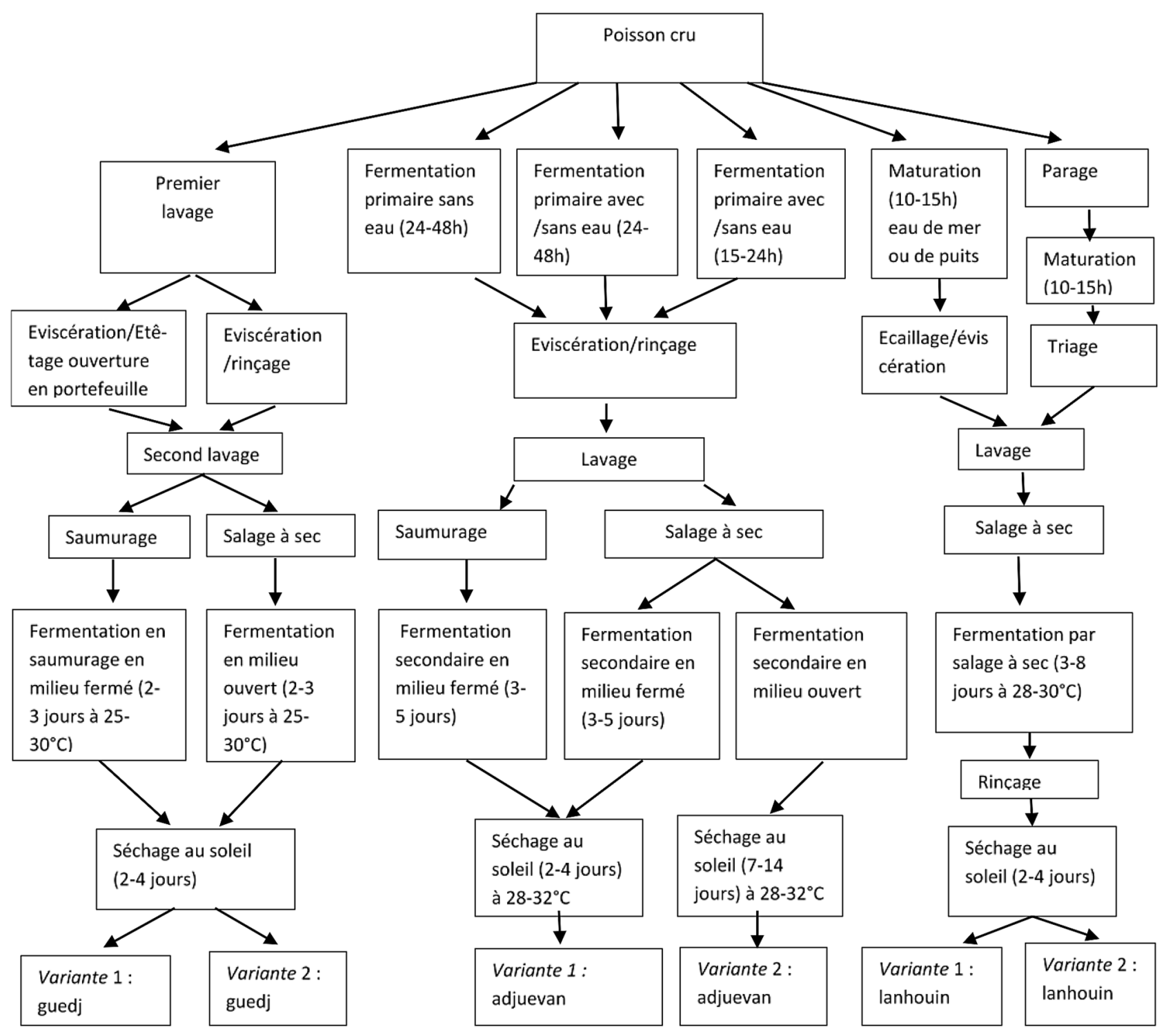

Fig. 1. Procédés de production du guedj, du lanhouin et de l'adjuevan.

Fig. 1. Processes for the production of guedj, lanhouin and adjuevan.

\section{Technologies de fermentation des poissons locaux}

Les trois types de produits étudiés sont comparables au momoni du Ghana (Sanni et al., 2002) et au plaa-som de Thaillande (Kopermsub et Yunchalard, 2010), au regard de la texture finale. Les résultats des études réalisées sur les procédés de production montrent que chaque type de produit (guedj, adjuevan et lanhouin) comporte deux variantes qui fournissent presque le même type de produit fermenté (Anihouvi et al., 2005; Kouakou et al., 2013 ; Fall et al., 2014). Le guedj et le lanhouin peuvent suivre deux procédés de production différents, tandis que l'adjuevan peut en suivre trois. Tous les procédés de production incluent des étapes de lavage, d'éviscération, de salage, de fermentation et de séchage, selon un ordre de succession variable (Fig. 1).

\subsection{Le lavage, l'éviscération et le rinçage}

Pour les trois types de produits, un parage du poisson est effectué, comprenant l'écaillage, l'éviscération, l'ouverture en portefeuille (pour les gros poissons seulement) et le rinçage. Le moment du parage est variable selon le produit et même pour ses variantes (Fig. 1). Le parage est généralement réalisé à l'aide d'un couteau. L'ouverture en portefeuille consiste à pratiquer soit une fente dans le ventre juste au-dessous de l'opercule, soit une ouverture intégrale du poisson le long de la colonne vertébrale sans élimination des nageoires et des branchies. Le lavage des 
poissons est fait avec de l'eau du robinet, de mer ou de puits (Anihouvi et al., 2005; Kouakou et al., 2013; Fall et al., 2014).

\subsection{La maturation}

Seule la fabrication du lanhouin inclut une phase de maturation. Celle-ci consiste à laisser le poisson sans traitement jusqu'à son ramollissement. Les tissus subissent un processus de dégradation sous l'action d'enzymes principalement protéolytiques et de micro-organismes. Pour l'une des variantes du lanhouin, les poissons non parés sont soumis à une maturation sans immersion dans une bassine. Pour l'autre, les poissons préalablement parés subissent une maturation par immersion dans une bassine d'eau de mer ou de puits. Lorsque la maturation est réalisée sans immersion, un triage est effectué à son terme pour sélectionner uniquement les poissons mous. La maturation dure 10 à $15 \mathrm{~h}$ pour les deux variantes. Au terme de la maturation, le poisson n'est plus rigide. Anihouvi et al. (2005) ont montré que les transformateurs considèrent cette étape comme très importante car elle influe sur la texture et l'arôme du lanhouin.

Toutefois, cette maturation assez longue à une température ambiante variant de 25 à $32^{\circ} \mathrm{C}$ en zone sahélienne ou tropicale peut entraîner une multiplication de micro-organismes indésirables. Diop et al. (2009b) ont montré que la maturation de la chair du poisson cru à cette gamme de température entraîne une prolifération in situ plus rapide $\left(10^{9} \mathrm{UFC} / \mathrm{g}\right) \mathrm{des}$ entérobactéries par rapport aux bactéries lactiques. Les entérobactéries comprennent des espèces incluant des souches pathogènes, putréfiantes ou décarboxylases positives susceptibles de contribuer aux problèmes de sureté sanitaire (Olsen et al., 2000) et à des défauts de qualité sensorielle. Diop et al. (2016) ont montré la nécessité de combiner l'utilisation du sel à une incubation à froid $\left(8^{\circ} \mathrm{C}\right)$ pour un meilleur contrôle des entérobactéries. Cette considération doit être prise en compte pour garantir l'hygiène durant le ramollissement du poisson.

\subsection{Le salage}

Le sel (chlorure de sodium) est généralement le seul agent technologique utilisé pendant la fermentation du guedj (Lo, 1993 ; Diop et al., 2009a), du lanhouin (Anihouvi et al., 2005) et de l'adjuevan (Kouakou et al., 2013). Le salage se fait soit en saumure pour les espèces grasses, soit à sec pour les espèces maigres. Pour le guedj et l'adjuevan, les deux techniques de salage sont utilisées (Fig. 1); pour le lanhouin, seul le salage à sec est pratiqué.

Le salage à sec consiste à appliquer le sel directement à la surface du poisson, dans les branchies et sous l'opercule par frottement ou saupoudrage. Le salage par saumurage consiste à immerger le poisson dans une solution saturée de sel. L'absorption du sel dépend de nombreux facteurs (espèce, type de muscle, taille des poissons, épaisseur de filet, poids, méthode de salage, concentration de la saumure, etc.) (GallartJornet et al., 2007). La pénétration du sel est plus rapide dans le cas du salage à sec, comparé au salage en saumurage (Nout et al., 2003; Boudhrioua et al., 2009).

Les quantités de sel utilisées en salage à sec ou en saumure varient en fonction des procédés. Concernant le lanhouin
(Anihouvi et al., 2005), pour lequel on effectue un salage à sec, les quantités de sel utilisées varient de 15 à $35 \%$ du poids du poisson $(\mathrm{m} / \mathrm{m}$, qui correspond au rapport masse du sel/masse du poisson). Dans le cas de l'adjuevan, pour lequel le salage par saumurage est plus répandu que le salage à sec (Kouakou et al., 2013), les concentrations en sel dans les solutions d'immersion varient de 20 à $35 \%(\mathrm{~m} / \mathrm{v}$, qui correspond au rapport masse du sel/volume d'eau). Concernant le guedj (Gret et CTA, 1993) dont les modalités de salage sont semblables à celles de l'adjuevan, les concentrations en sel dans les solutions d'immersion sont généralement supérieures à $30 \%$ $(\mathrm{m} / \mathrm{v})$ et atteignent souvent $80 \%(\mathrm{~m} / \mathrm{v})$.

Pour les trois types de produits, un second salage, moins important que ceux réalisés durant la fermentation, est souvent pratiqué en prélude au séchage afin de diminuer la teneur en eau du poisson et de limiter les attaques d'insectes. Pour le lanhouin, le sel ajouté ne représente que 15 à $25 \%(\mathrm{~m} / \mathrm{m})$ de la quantité utilisée dans le premier salage, tandis que pour le guedj et l'adjuevan, les quantités additionnelles ne sont pas définies; elles sont laissées à l'appréciation des transformateurs. Selon Anihouvi et al. (2005), ce deuxième salage est réalisé pour améliorer la couleur et faciliter la commercialisation du lanhouin.

Des études ont montré que lorsque la teneur en sel atteint 20 à $30 \%(\mathrm{~m} / \mathrm{m})$ du poids, le nombre de bactéries présentes pendant la fermentation diminue et le poisson garde ses caractéristiques recherchées (Anupam et al., 2009). Toutefois, certaines communautés microbiennes comme les bactéries lactiques halophiles se multiplient malgré le salage, contribuant à une baisse du pH (Diop et al., 2016). Selon Sefa-Dedeh et Youngs (1976), des espèces comme Streptococcus sp. et Corynebacterium sp., retrouvées dans les produits, pourraient provenir du sel utilisé pour le traitement des poissons. De plus, Kouakou et al. (2013) ont révélé que ces deux salages successifs affectaient la qualité organoleptique et sanitaire des produits. De nos jours, la tendance est de réduire la quantité de sel dans les produits carnés pour des considérations tant technologiques que diététiques (Kanner et al., 1991).

\subsection{Approches de fermentation, durée et profil microbien}

Le guedj, le lanhouin et l'adjuevan conservent sensiblement leur forme originale de poissons entiers ou ouverts en portefeuille après fermentation (Essuman, 1992; Anihouvi et al., 2005 ; Diop et al., 2010 ; Kouakou et al., 2013) (Figs. 2 et 3 ). De par ce caractère, ils sont assimilables au lafi de Guinée (Montel et al., 2005) et au pla-ra de Thaillande (Tanasupawat et al., 2007). Pour les trois types de produits, la fermentation s'effectue de façon identique dans différents types de matériels rudimentaires (citernes, bidons, jarres, bassines, sur des claies de séchage), susceptibles d'être une source potentielle de contamination microbienne et chimique.

Les études sur les procédés de production ont montré que la fermentation traditionnelle est spontanée. Elle se fait en combinaison avec un salage du poisson à sec ou par saumurage, en milieu ouvert ou fermé selon la variante du type de produit. La fermentation par salage à sec est la seule utilisée pour le lanhouin, tandis que pour le guedj et l'adjuevan, les poissons peuvent être soumis aux deux 


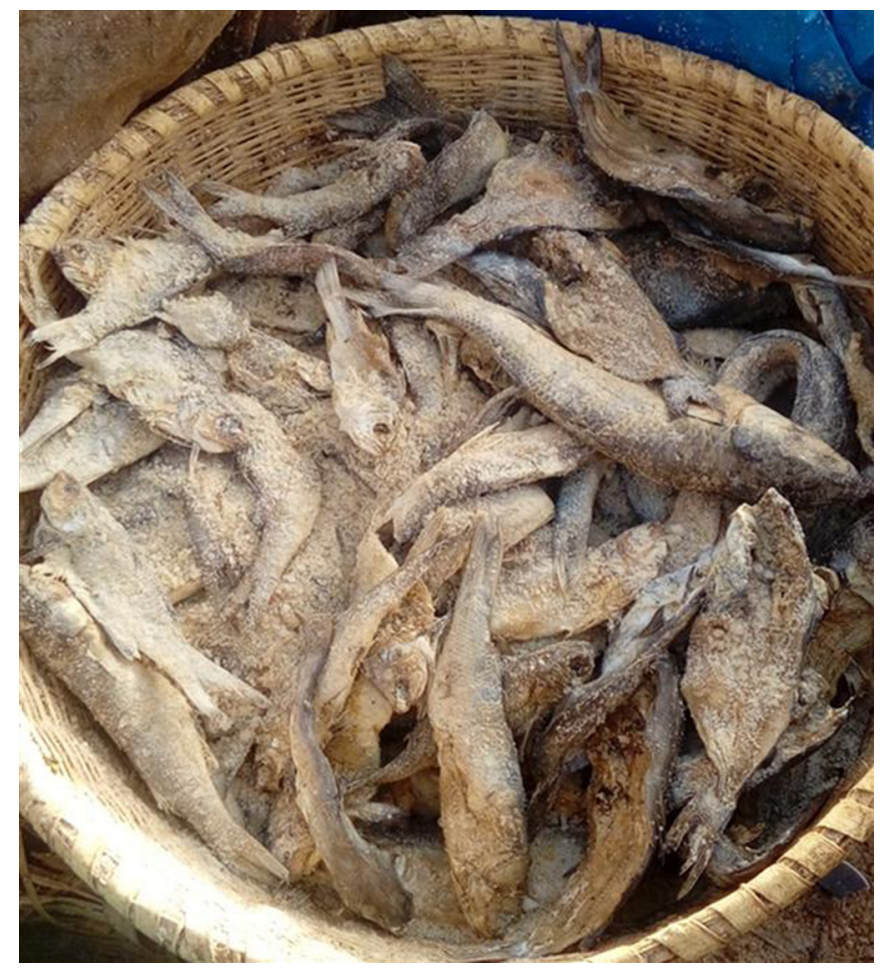

Fig. 2. Poissons transformés par fermentation traditionnelle et salage à sec au Sénégal.

Fig. 2. Fish processed by traditional fermentation and dry salting.

approches de fermentation (Anihouvi et al., 2006; Kouakou et al., 2013; Fall et al., 2014). À la différence du guedj et du lanhouin, la production de l'adjuevan nécessite une étape de fermentation primaire. Cette fermentation primaire s'effectue avant le parage. Pour cela, le poisson cru est laissé se décomposer avec ou sans eau de mer jusqu'à un ramollissement complet de la chair. La durée de cette fermentation est de 15 à $48 \mathrm{~h}$ selon la variante (Kouakou et al., 2013).

La technique de fermentation par salage à sec, généralement réalisée sur les poissons de petite taille, traités en entier, est similaire pour les trois types de produits. Les poissons sont salés et disposés sur du matériel de jute, des emballages de récupération ou de grands plastiques noirs maintenus par des pierres, sur des claies de séchage ou sur des filets (Anihouvi et al., 2005 ; Kouakou et al., 2013 ; Fall et al., 2014). Ce type de fermentation se réalise simultanément au séchage. Elle est similaire à celle effectuée pour le momoni (Eyo, 1991; Sanni et al., 2002). Elle est considérée comme plus économique du fait de la réutilisation du sel dans le cas de plusieurs lots de fermentations successives. Cependant, selon Beddows (1985), le sel réutilisé sans lavage peut être une source de contamination microbienne lorsqu'il est conservé dans des conditions insalubres. Dans d'autres pratiques de fermentation par salage à sec, qui tendent à disparaître de nos jours en raison de problèmes hygiéniques, les poissons sont enfouis dans une fosse pouvant atteindre deux mètres de profondeur, refermée avec du sable. Cela est pratiqué pour le lanhouin (DossouYovo, 2002; Anihouvi et al., 2005).

Pour la fermentation par saumurage, les quantités de sel et le volume de la solution d'immersion (eau du robinet, eau de

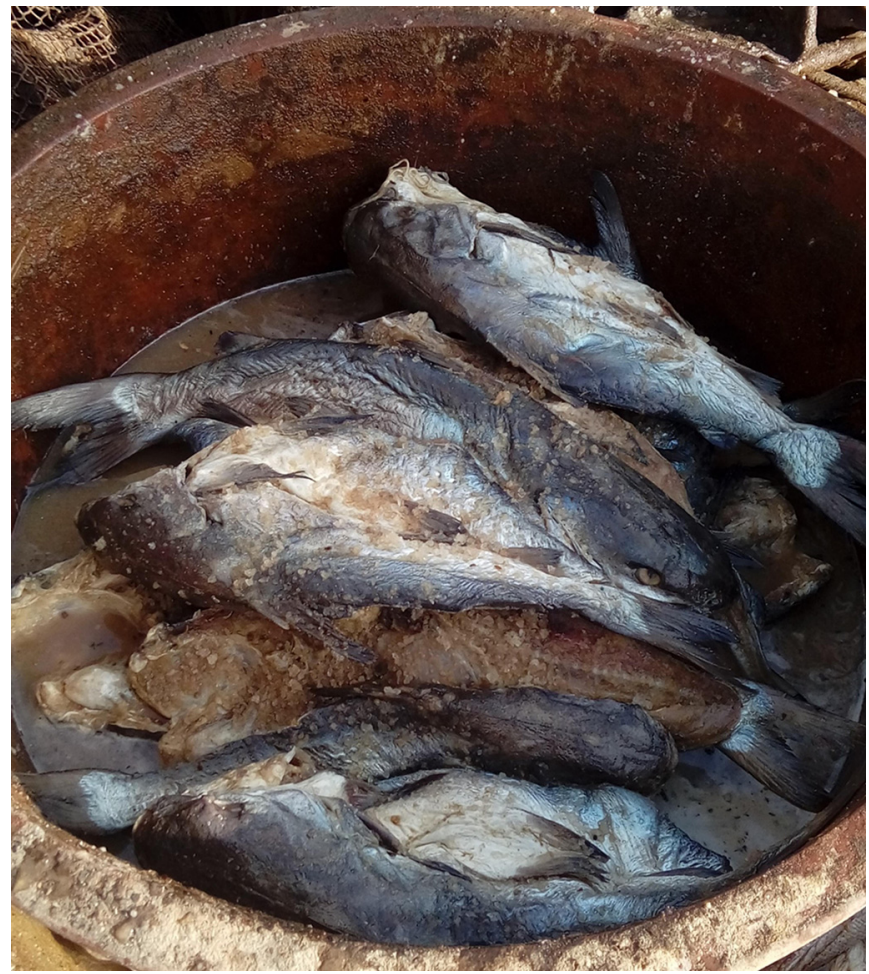

Fig. 3. Fermentation par saumurage de poissons ouverts en portefeuille dans une bassine.

Fig. 3. Fermentation by brining of open fishes in a basin.

puits ou eau de mer) sont estimés visuellement par les transformateurs (Anihouvi et al., 2005; Kouakou et al., 2013 ; Fall et al., 2014). Les saumures ne sont pas souvent renouvelées ou purifiées entre deux fermentations dans les sites de production; cette pratique peut entraîner une contamination croisée du produit (Horner, 1997). L'ajout massif de sel entraîne une diminution de la vitesse de fermentation (Adams et al., 1987). De plus, pour des quantités de sel identiques, la teneur en sel du poisson diminue logiquement lorsque le taux de lipides augmente (GallartJornet et al., 2007).

La durée de la fermentation varie en fonction du type de produit, de la taille des poissons, de la quantité de poissons et de la demande du marché. Elle est plus longue (3 à 8 jours) pour le lanhouin (Beddows, 1985; Anihouvi et al., 2005), moyenne (3 à 5 jours) pour l'adjuevan (Kouakou et al., 2013) et plus courte ( 2 à 3 jours) pour le guedj (Fall et al., 2014). La durée de fermentation du lanhouin est comparable à celle du momoni (Sanni et al., 2002), tandis que celle du guedj est similaire à celle d'un produit fermenté typique du Ghana comme le Koobi (Anihouvi et al., 2012a). Cependant, la durée de fermentation des produits étudiés est moindre que celles décrites pour les poissons fermentés en Asie du Sud-Est. Ces derniers ont une durée de fermentation variant de 12 jours à un an, comme dans les cas du yulu, kapi et plaa-som (PalludanMüller et al., 2002; Jin-Jin et al., 2007; Nandhsha et al., 2009).

La fermentation des produits s'effectue à température ambiante pour les trois produits. Lorsque l'on considère les saisons les plus chaudes dans les trois pays étudiés, la 
fermentation du guedj, du lanhouin et de l'adjuevan se fait respectivement entre $25-30,28-30$ et $28-32^{\circ} \mathrm{C}$ (Anihouvi et al., 2006; Kouakou et al., 2013; Fall et al., 2014).

Plusieurs espèces interviennent dans la fermentation des produits ciblés. Le lanhouin et l'adjuevan ont en commun la présence du genre Streptococcus sp. (Koffi-Nervy et al., 2011; Anihouvi et al., 2012a). Le guedj et le lanhouin renferment les genres Staphylococcus sp., Micrococcus sp. et Bacillus sp. (Anihouvi et al., 2012a). Les germes comme Staphylococcus sp. et Bacillus sp. sont présents en général dans les poissons des eaux chaudes et peuvent provenir également du sel utilisé. À une certaine concentration de sel (7\%), la croissance des bactéries lactiques est inhibée (Horner, 1997). De plus, plusieurs études ont montré que les Micrococcus et Bacillus trouvés dans le lanhouin sont caractéristiques d'une fermentation alcaline (Yankah, 1988; Sanni et al., 2002; Achinewhu et al., 2004; Anihouvi et al., 2007). Les genres trouvés dans l'adjuevan sont similaires à ceux rapportés dans la fermentation des poissons additionnés de sources de glucides (riz) comme le pla-ra et le plaa-som (Yachai et al., 2008). Par contre, ceux trouvés dans le lanhouin et le guedj sont similaires aux genres présents dans la plupart des produits fermentés comme le momoni (Sanni et al., 2002).

En Afrique de l'Ouest, la nature spontanée de la fermentation entraîne des inconvénients liés au manque de contrôle des processus. Les produits obtenus sont de qualité très fluctuante et la durée de fermentation est longue (Anihouvi et al., 2006; Kouakou et al., 2013; Fall et al., 2014). Pour un contrôle plus efficient de cette étape, il est nécessaire de développer des méthodes d'amélioration incluant une réduction de la durée de fermentation.

\subsection{Le séchage}

Le séchage se fait de manière traditionnelle et identique pour les produits étudiés. Il est réalisé sur des claies en bois de rônier disposées sur des piquets, sur des filets de récupération, sur des nattes, des herbes, à même le sol ou sur des filets disposés sur des cailloux (Anihouvi et al., 2005; Kouakou et al., 2013 ; Fall et al., 2014) (Fig. 4). Le matériel rudimentaire utilisé pour le séchage ne permet pas une bonne circulation de l'air. Le séchage dure 2 à 4 jours pour toutes les variantes des trois types de produits sauf pour une variante de l'adjuevan, où elle dure 7 à 14 jours (Kouakou et al., 2013). Les poissons mis à sécher sont retournés à la mi-journée. À la fin de la journée, les produits sont empilés et couverts de matériels rudimentaires de récupération pour empêcher une reprise de l'humidité des produits durant la nuit. La température de séchage du lanhouin et du guedj n'est pas définie dans la littérature. Toutefois, les températures moyennes annuelles minimales et maximales indiquées dans les documents de relevés météorologiques pour l'année 2018 sont respectivement de 26,5 et $34,5^{\circ} \mathrm{C}$ pour le Sénégal et de 28,4 et $34,3^{\circ} \mathrm{C}$ pour le Bénin (Historique-météo, 2018). Elles peuvent servir de référence, étant donné que ces produits sont séchés à la température ambiante. Pour l'adjuevan, la température de séchage varie entre 28 et $32^{\circ} \mathrm{C}$ selon la variante (Kouakou et al., 2013).

Des études ont montré que le séchage empêche le développement rapide des micro-organismes et surtout la poursuite des réactions enzymatiques durant la conservation

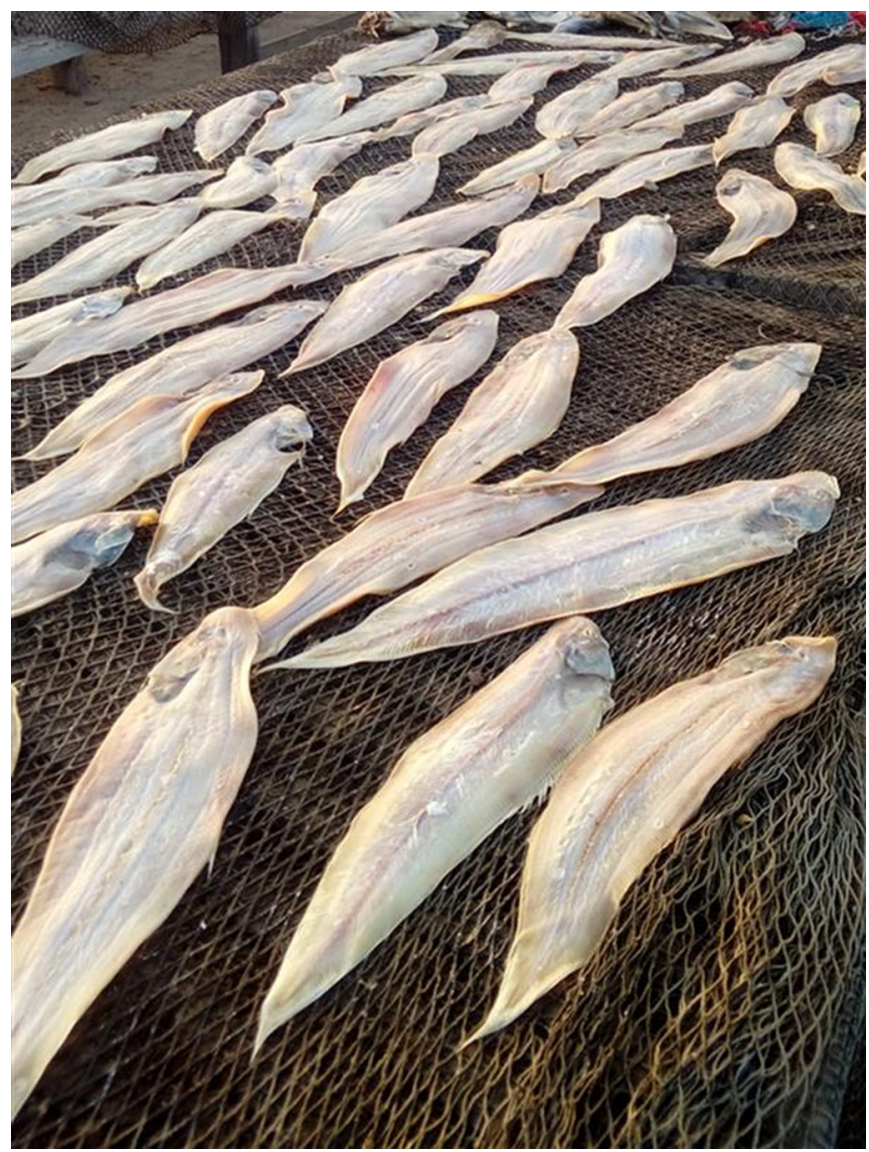

Fig. 4. Séchage des poissons sur un filet de récupération.

Fig. 4. Drying fish on a salvage net.

(Oksuz et al., 2008). La croissance microbienne et les réactions enzymatiques favorisées par l'humidité seraient responsables d'une modification négative de la qualité organoleptique et sanitaire. Au cours du séchage, les produits étudiés sont exposés aux insectes, à la poussière, à la contamination chimique et microbienne. Pour lever ces contraintes, certains producteurs utilisent sur les produits fermentés des produits chimiques impropres à l'alimentation humaine. Anihouvi et al. (2005) ont rapporté que le lanhouin est parfois rincé avec de l'eau de mer additionnée de quelques gouttes de pétrole ou d'essence en prélude au séchage.

Toutes ces pratiques non standardisées constatées à toutes les étapes de la production affectent la qualité des produits. Ce manque d'hygiène dans la production est également constaté dans la production du poisson fermenté Chepa Shutki du Bangladesh (Nayeem et al., 2010).

\section{Qualité physico-chimique et microbiologique des produits}

Les caractères physico-chimiques et microbiologiques des produits ciblés sont très variables selon plusieurs études réalisées ces dernières années.

$\mathrm{Au}$ plan biochimique, les études ont montré que le lanhouin, le guedj et l'adjuevan présentent respectivement des $\mathrm{pH}$ compris entre 6,8-7,9,6,4-6,5 et 6,4-6,6 (Anihouvi et al., 
2005 ; Kouakou et al., 2013; Fall et al., 2017). Concernant le lanhouin présentant un $\mathrm{pH}$ supérieur à 7 , des valeurs similaires ont été décrites pour le momoni (Nerquaye-Tetteh et al., 1978 ; Abbey et al., 1994; Yankah, 1988) et l'oued Betok, poisson fermenté traditionnel du Sud Kalimantan, en Indonésie (Petrus et Hardoko, 2013). Pour le guedj et l'adjuevan, le $\mathrm{pH}$ est inférieur à 7. Des résultats similaires ont été rapportés sur un poisson fermenté en Thaïlande, le pedah siam, sur le momoni et sur un poisson fermenté au Ghana (FAO, 1971; Sanni et al., 2002). Koffi-Nevry et Koussémon (2012) ont rapporté des valeurs de $\mathrm{pH}$ plus basses pour l'adjuevan $(5,3)$. Cela montre que le $\mathrm{pH}$ est très variable d'un produit à un autre et au sein d'un même type de produit comme l'adjuevan. Les valeurs de $\mathrm{pH}$ proches de la neutralité ou basiques peuvent avoir un impact sur la qualité des produits ciblés (Yankah, 1988). Elles sont favorables au développement de certains micro-organismes comme les enterobactéries lors d'une exposition à la température ambiante en zone tropicale. Ce groupe peut contenir des germes responsables de mauvaises odeurs ou pathogènes (Jay et al., 2005). Le pH final est donc un résultat émanant d'un équilibre complexe entre l'acidité produite par les bactéries lactiques et les composés aminés basiques produits lors de l'hydrolyse des protéines.

La teneur en eau des trois types de produits est supérieure à $50 \%$. Elle est plus élevée pour l'adjuevan $(68,9 \%$ ) (KoffiNevry et Koussémon, 2012), atteint $53,4 \%$ pour le lanhouin (Anihouvi et al., 2005) et est plus faible pour le guedj (50,3\%) (Fall et al., 2014). Ces teneurs en eau ne permettent pas de préserver les produits alimentaires de la multiplication de micro-organismes indésirables (Troller et Christian, 1978). Il est noté que les poissons fermentés sont rarement conservés au froid dans les systèmes de transformation halieutique et de commercialisation en Afrique de l'Ouest.

L'ABVT (Azote basique volatil total) reflète une faible dégradation biochimique des protéines au cours de la transformation (Kerr et al., 2002). Les teneurs maximales en ABVT sont inférieures à $500 \mathrm{mg} \mathrm{N} / 100 \mathrm{~g}$ pour les trois types de produits, seuil admis pour les produits transformés de poissons (Silva et al., 1998). Des valeurs similaires ont été rapportées sur le momoni et d'autres produits halieutiques fermentés (Yankah, 1998; Nerquaye-Tetteh et al., 1978; Abbey et al., 1994). Elles renseignent aussi sur la valeur nutritionnelle des produits (Pearson, 1976; Horner, 1997). Lorsque les teneurs sont supérieures à $500 \mathrm{mg} \mathrm{N} / 100 \mathrm{~g}$, le produit halieutique transformé est considéré comme impropre à la consommation humaine (Silva et al., 1998).

La concentration en sel dans les produits étudiés est variable et est de $(7,7-10,7 \%),(5,2-10,3 \%)$ et $(5,2-7,3 \%)$ respectivement pour le guedj (Fall et al., 2017), l'adjuevan (Kouakou et al., 2013) et le lanhouin (Anihouvi et al., 2006). Des valeurs supérieures ou inférieures ont été rapportées sur le momoni (Nerquaye-Tetteh et al., 1978; Abbey et al., 1994). Ces teneurs en sels élevées peuvent s'expliquer par les quantités massives de sel utilisées pendant la fermentation et le séchage.

Les teneurs en protéines de l'adjuevan (Koffi-Nevry et Koussémon, 2012), du lanhouin (Anihouvi et al., 2005; Anihouvi et al., 2006) et du guedj (Fall et al., 2014) atteignent respectivement 49,3, 25 et 28,7\%. Fall et al. (2017) ont rapporté un taux de protéines de $35,5 \%$ pour le guedj. Cette différence peut s'expliquer par la nature des poissons utilisés, dont la teneur en protéines peut varier entre 18 et $72 \%$ (El Sheikha et al., 2013).
La présence d'histamine, une amine biogénique dont la teneur maximale est fixée par norme, a été déterminée dans les trois produits fermentés ciblés. L'histamine peut provoquer des effets néfastes chez les consommateurs de produits halieutiques, allant d'irritations jusqu'à la mort en cas de consommation à forte dose. La teneur maximale autorisée est de $20 \mathrm{mg} / 100 \mathrm{~g}$ (Kerr et al., 2002). Les teneurs en histamine déterminées pour le lanhouin sont 28,7 et $27,2 \mathrm{mg} / 100 \mathrm{~g}$ (Anihouvi et al., 2005; Anihouvi et al., 2006). Pour le guedj et l'adjuevan, des teneurs plus faibles ou inférieures à $20 \mathrm{mg} / 100 \mathrm{~g}$ ont été mesurées (Fall et al., 2014; Kouakou et al., 2013). Les valeurs élevées d'histamine constatées pour le lanhouin peuvent s'expliquer par la faible teneur en sel par rapport au guedj et à l'adjuevan, unique moyen de limiter la croissance des micro-organismes ayant une capacité de décarboxylation impliqués dans la formation d'histamine (Hanson et al., 1985; Ababouch, 1990; Ahmed, 1991 ; Silva et al., 1998).

Les résultats des études microbiologiques sur les produits fermentés locaux ont montré que la flore mésophile aérobie totale (FMAT) a été évaluée à $5,2,5,9$ et $6,5 \log _{10} \mathrm{UFC} / \mathrm{g}$ respectivement pour le guedj, l'adjuevan et le lanhouin (Anihouvi et al., 2005 ; Koffi-Nevry et Koussémon, 2012; Fall et al., 2014). Pour le guedj, des valeurs supérieures à $7,9 \log _{10}$ UFC/g ont été rapportées par d'autres études (Lo, 1993). La différence entre les quantités microbiennes rapportées pour le guedj par ces deux études peut s'expliquer par la variabilité des matrices de départ (poisson cru), l'hygiène au cours de la transformation, la durée de fermentation, la conservation et la commercialisation. Les quantités de levures et moisissures dans le guedj et l'adjuevan ont été déterminées à 2,17 et $1,5 \log _{10} \mathrm{UFC} / \mathrm{g}$ respectivement (Koffi-Nevry et Koussémon, 2012; Fall et al., 2017), tandis que pour le lanhouin, seules les moisissures ont été mises en évidence à un niveau inférieur à $1 \log _{10}$ UFC/g (Anihouvi et al., 2006). Concernant les bactéries lactiques, des quantités de $6,5,4$ à 6,3 et $4 \log _{10}$ $\mathrm{UFC} / \mathrm{g}$ ont été déterminées respectivement pour le guedj, le lanhouin et l'adjuevan (Anihouvi et al., 2006; Koffi-Nevry et Koussémon, 2012; Fall et al., 2017). Des valeurs similaires à celles trouvées par Fall et al. (2017) avaient déjà été rapportées pour le guedj par Dortu (2002). Les bactéries lactiques dominent en général dans de nombreux produits fermentés. Elles assurent la fermentation du poisson en entraînant une diminution $\mathrm{du} \mathrm{pH}$ par production d'acides organiques contribuant à l'amélioration du goût, de l'arôme et de la texture, mais aussi à la qualité et à la sécurité du produit (Kandler, 1983 ; Saisithi et al., 1986 ; Ostergaard et al., 1998). L'absence de Salmonella dans les trois produits peut rassurer les consommateurs (Anihouvi et al., 2005; Anihouvi et al., 2006; Kouakou et al., 2013; Fall et al., 2014; Fall et al., 2017). Selon Smita et al. (2011), les Salmonella sont généralement absentes des poissons fermentés. Cependant, la présence de Clostridium, Staphylococcus et coliformes thermo-tolérants dans ces produits fermentés indique la nécessité de prendre des mesures d'hygiène susceptibles de contrer les risques liés à ces types de micro-organismes (Essuman, 1992; Anihouvi et al., 2006 ; Kouakou et al., 2013 ; Fall et al., 2017). Ces derniers sont capables transformer des acides aminés libres en amines biogéniques comme l'histamine (Kerr et al., 2002; Tsai et al., 2006).

Pour chaque type de produit, des espèces microbiennes majoritaires ont été notées. Bacillus sp. et Micrococcus sp. sont 
présentes de manière assez importante $\left(5,4\right.$ et $\left.4,1 \log _{10} \mathrm{UFC} / \mathrm{g}\right)$ dans le lanhouin produit avec une espèce comme Scomberomorus tritor (Anihouvi et al., 2006; Anihouvi et al., 2007 ; Anihouvi et al., 2012a). Pour l'adjuevan, les espèces dominantes sont Lactobacillus sp., Lactococcus sp., Pediococcus sp., Pediococcus sp., streptococcus sp., Enterobacter, Pseudomonas sp. et Klebsiella sp. (Nerquaye-Tetteh et al., 1978; Essuman, 1992; Koffi-Nervy et al., 2011; Anihouvi et al., 2012a; Koffi-Nevry et Koussémon, 2012; Kouakou et al., 2012b). Pour le guedj, Proteus spp., Shewanella putrefaciens, Bacillus spp. sont plus importantes (Essuman, 1992; Diop, 2008; Anihouvi et al., 2012a).

Ces résultats très variables des études sur les poissons fermentés en Afrique de l'Ouest montrent la nécessité de développer des études pour chaque produit dans chaque pays en tenant compte du type de poissons, des conditions climatiques, du goût recherché, du coût, de la nature et de la durée de fermentation et du séchage.

\section{Amélioration des procédés de fabrication du poisson fermenté en Afrique de l'Ouest}

Plusieurs auteurs ont montré que les micro-organismes principaux contenus dans les produits peuvent être utilisés comme starter (Riebroy et al., 2008; Zaman et al., 2010). Le starter permet de mieux contrôler la fermentation et de standardiser le procédé de production (Holzapfel, 2002). Les bactéries lactiques peuvent être utilisées comme cultures de départ. En Afrique de l'Ouest, des bactéries lactiques ont été isolées dans divers types de produits obtenus à partir de la fermentation spontanée de céréales (maïs, mil, sorgho), poissons ou racines alimentaires (Olasupo et al., 1996; Agati et al., 1998; Hounhouigan et al., 1999; Sanni et al., 2002; Kostinek et al., 2005 ; Oguntoyinbo, 2007 ; Diop et al., 2007 ; Vieira-Dalode et al., 2007; Yao et al., 2009).

Pour les trois produits étudiés, plusieurs initiatives sont entreprises pour améliorer la technologie de fermentation.

Pour le lanhouin, des études ont rapporté que l'utilisation d'une culture de départ de Lactobacillus plantarum diluée en série $\left(10^{-1}\right.$ à $\left.10^{-5} \mathrm{UFC} / \mathrm{g}\right)$ dans une solution stérile de Ringer sur des espèces de poissons comme Pseudotolithus senegalensis et Scomberomorus tritor a permis une baisse du $\mathrm{pH}$ de 6,41 à 6,05 et une inhibition de la microflore indésirable (Dossou-Yovo et al., 2011). Les bactéries lactiques, en acidifiant le produit, permettent un meilleur contrôle de la fermentation (Mauguin et Novel, 1994 ; Annan et al., 2003). Elles n'affectent pas le processus de maturation mais inhibent seulement la microflore pathogène (Halm et al., 2004). D'autres travaux ont permis de mettre au point un ferment de type traditionnel pour le contrôle des phases de maturation et de fermentation (Anihouvi et al., 2012c). Ce ferment a entraîné une réduction significative de la durée de fermentation et une amélioration de la qualité sanitaire du produit. Avec cette technique, le goût et l'arôme du lanhouin deviennent agréables, contrairement à la fermentation traditionnelle avec laquelle le produit développe une certaine odeur et un goût fort (Anihouvi et al., 2006).

Pour le guedj au Sénégal, les recherches effectuées sont basées sur la sélection de bactéries lactiques développant une activité bactéricide et dépourvues d'activité de décarboxylation, pour prévenir la production d'amines biogéniques au cours de la fermentation. Ces études ont montré que Lactococcus lactis subsp. lactis CWBI-B1410, bactérie nisinogène isolée de la farine de mil fermentée (Diop et al., 2007), peut être appliqué à la fermentation ou à la conservation de la chair de poisson conditionnée artisanalement au Sénégal. Deux modalités ont été testées. La première a porté sur l'utilisation de Lactococcus lactis subsp. lactis CBI-B1410 nisinogène comme culture de départ sur la chair du poisson additionnée de glucose (Diop et al., 2009b) pour une fermentation à la température ambiante $\left(25-30^{\circ} \mathrm{C}\right)$. Une seconde modalité est l'immersion de la chair du poisson dans une culture de la souche nisinogène ciblée sur un milieu à base de farine de mil. Cette technique entraîne une meilleure acidification, parallèlement à une activité bactéricide permettant de limiter significativement la multiplication respective des entérobactéries et de Listeria monocytogenes (Diop et al., 2015). Des études complémentaires ont permis de déceler un effet bactéricide du surnageant de culture neutralisé issu de Lactococcus lactis subsp. lactis CWBI-B1410 en combinaison avec du chlorure de sodium $(\mathrm{NaCl})$ sur des filets incubés à $10^{\circ} \mathrm{C}$ (Diop et al., 2009a ; Diop et al., 2016). Toutefois, cette pratique de conservation à froid n'est pas répandue au Sénégal en raison du coût de la consommation énergétique qu'elle requiert. Cela justifie la nécessité d'axer la recherche sur des technologies de fermentation améliorée par l'utilisation de bactéries lactiques bactéricides et décarboxylases négatives comme culture de départ, dans la perspective d'un impact sociétal.

Pour l'adjuevan en Côte d'Ivoire, des travaux ont montré que l'emploi de méthodes moléculaires d'analyse de l'écologie microbienne (Polymerase chain reaction denaturing gradient gel electrophoresis [PCR-DGGE]) peut contribuer à la caractérisation des levures dans le produit. Kouakou et al. (2012a) ont identifié sur l'adjuevan des espèces de levures telles que Kluyveromyces marxianus, Hansenula anomala, Saccharomyces cerevisiae, Candida tropicalis, Candida zeylanoides, Pichia fermentans, Debaromyces hansenii, Hanseniaspora osmophile et Rhodotorula glutinis, qui n'avaient pas été décrites dans les poissons fermentés. Des espèces similaires, $H$. anomala et $D$. hansenii, ont été trouvées dans le poisson fermenté du Ghana (Sanni et al., 2002). Des études ont montré que la croissance des levures sur les produits alimentaires pourrait jouer un effet bénéfique ou inhibiteur sur certaines bactéries sporulées comme Clostridium butyricum et Clostridium tyrobutyricum (Fatichenti et al., 1983 ; Lopandic et al., 2006). De plus, les levures peuvent contribuer à l'amélioration de la qualité sensorielle et hygiénique des poissons fermentés, comme dans le cas des fromages et des produits carnés séchés à sec (Bolumar et al., 2006; Martin et al., 2006; Fleet, 2007; Andrade et al., 2009). D'autres études, basées sur la caractérisation des bactéries lactiques et la composition des acides aminés libres, ont permis une différenciation des bactéries lactiques dans les deux méthodes de production de l'adjuevan. Les résultats de ces études ont montré que l'utilisation d'une culture de bactéries lactiques comme L. fermentum, L. lactis, L. pseudomesenteroides, L. raffinolactis, L. lactis subsp. cremoris pourrait être potentiellement bénéfique pour améliorer la flaveur et la qualité nutritionnelle de l'adjuevan (Kouakou et al., 2012b).

L'ensemble de ces études constitue une base de développements technologiques susceptibles de répondre au défi sociétal de la qualité des poissons fermentés locaux dans les pays ciblés. 


\section{Défis sociétaux pour l'amélioration qualitative des poissons fermentés locaux}

Les poissons fermentés de type guedj, lanhouin et adjuevan contribuent à la diversification de l'offre locale de ressources alimentaires riches en protéines d'origine animale, dans les centres urbains, en milieu rural et pour la diaspora originaire d'Afrique de l'Ouest dans les pays développés. Mais du fait de leur qualité hygiénique douteuse, les produits étudiés ne sont pas encore commercialisés dans les circuits conventionnels. Traditionnellement, la matière première de base utilisée pour alimenter la filière de ces produits fermentés locaux est constituée de mises à terre invendues par le biais du mareyage ou d'espèces à faible valeur commerciale (Gret et CTA, 1993 ; Ba, 2005 ; Anihouvi et al., 2012a; Kouakou et al., 2013). En plus de la fermentation, le séchage traditionnel au soleil peut constituer une source de contamination additionnelle de par sa durée (Anihouvi et al., 2005 ; Kouakou et al., 2013; Fall et al., 2014). Pour que les produits puissent être commercialisés dans les circuits conventionnels, il est nécessaire de prendre des mesures correctives concernant les pratiques traditionnelles de stockage des captures, de fermentation et de séchage.

Des moyens technologiques de traitement post-capture et de séchage amélioré, adaptés au contexte socioéconomique des pays de l'Afrique de l'Ouest, ont déjà été élaborés (FAO, 2005 ; FAO, 2014). Le défi technologique majeur résiduel est celui de l'amélioration de la fermentation. Les résultats des recherches entreprises entre 2005 et 2017 sur les trois produits ciblés (Diop et al., 2009b; Dossou-Yovo et al., 2011 ; Kouakou et al., 2012a; Kouakou et al., 2012b; Diop et al., 2015) ont ouvert des perspectives technologiques susceptibles de renforcer la qualité des poissons fermentés. Toutefois, quelques défis technologiques complémentaires restent encore à relever pour chaque type de produit, notamment pour permettre l'applicabilité à grande échelle des fermentations améliorées dans les systèmes halieutiques locaux respectifs, pour un impact économique.

Pour le lanhouin, en plus des études sur la stabilité et la performance du ferment dans le temps, il est important d'améliorer la conduite de la maturation afin d'obtenir un produit de qualité sanitaire acceptable (Anihouvi et al., 2012b).

Pour le guedj, le nouveau défi est la mise au point d'un ferment adéquat à base de souches sélectionnées (Diop et al., 2007; Diop, 2008; Diop et al., 2009a; Diop et al., 2009b, 2015 ; Fall et al., 2017), peu coûteux, qui prenne en compte les facteurs locaux, à savoir la charge microbienne des poissons crus convenablement entreposés et la reconstitution de la matrice de fermentation à base de farine de mil, au regard de la disponibilité de cette céréale au Sénégal.

Pour l'adjuevan, des études devront être menées en vue d'une confirmation du rôle des bactéries et des levures prédominantes pendant la fermentation, afin de pouvoir les utiliser comme ferments. À cela, on peut ajouter des études sur l'analyse des amines biogéniques pendant la conservation des deux types d'adjuevan à différentes températures, pour connaître la température optimale et la durée limite de conservation (Kouakou et al., 2013).

Pour les trois produits, une meilleure vulgarisation des dispositifs de séchage élaborés dans le cadre des programmes antérieurs de l'Organisation des Nations Unies pour l'alimentation et l'agriculture (FAO) dans les pays concernés (Ndiaye et Diei-Ouadi, 2009), ainsi que la facilitation de leur acquisition dans les unités de transformation devraient permettre d'améliorer la qualité des produits finis.

La valorisation de l'ensemble des acquis techniques et technologiques pour un impact socioéconomique réel implique des actions à différents échelons dans chaque pays ciblé. À l'échelon sectoriel, le caractère collectif des démarches de qualification devra placer les organisations professionnelles de la pêche artisanale au centre du dispositif. Leurs rôles et leurs fonctions, au service de leurs membres, devront être renforcés par la formation des membres des organisations et par la construction de nouvelles compétences dans l'animation de projets collectifs de modernisation du secteur de la transformation. Ces projets porteront sur l'élaboration et la négociation au niveau interprofessionnel de règles concernant les modes de production. Ils porteront aussi sur la négociation avec les institutions publiques des aspects réglementaires et législatifs. À l'échelon territorial, ces processus d'innovation soulignent le rôle stratégique que peuvent jouer les activités de la pêche maritime dans le développement local des pays concernés.

\section{Conclusion}

En Afrique de l'Ouest, plusieurs produits halieutiques locaux issus de poissons fermentés, salés et séchés, sont proposés aux consommateurs et utilisés comme condiments, en particulier le guedj, le lanhouin et l'adjuevan. Cependant, la qualité de ces produits est souvent douteuse. Des technologies non standardisées, de la capture à la transformation, sont à l'origine de la variabilité des produits proposés. La recherche a contribué à l'amélioration de la fermentation pour le renforcement de la qualité des produits ciblés. Le développement de ces recherches et un transfert des technologies élaborées auprès des acteurs locaux, à travers des formations et des actions collectives, de la transformation du poisson constituent des défis sociétaux majeurs à relever pour assurer un meilleur impact économique au secteur de la transformation du poisson dans les pays concernés.

Remerciements. Cette recherche a été menée dans le cadre de l'initiative «Pôle de recherche en biotechnologie alimentaire et accompagnement pour la compétitivité»(PREBAAC), implanté dans la ferme agricole de l'université Gaston Berger (UGB) de Saint-Louis, et qui contribue au projet Erasmus +573791 «Défis sociétaux et gouvernance des universités africaines: le cas des aliments au Maroc, en République démocratique du Congo et au Sénégal (DAfrAli)».

Nous remercions les transformatrices d'un site de la région de Saint-Louis qui nous ont autorisé à prendre des photos de fermentations traditionnelles.

\section{References}

Ababouch L. 1990. Histamine in fishery products: a review. In: Proceedings of the FAO expert consultation on fish technology in Africa. Côte d'Ivoire: FAO-Fisheries Abidjan, pp. 44-50.

Abbey LD, Hodari-Okae M, Osei-Yaw A. 1994. Studies on traditional processing and quality of fermented fish "momone". Accra (Ghana): Food Research Institute, 48 p. 
Achinewhu S, Amadi E, Barimalaa S, Eke J. 2004. Microbiology of naturally fermented fish (Sardinella sp.). J Aquatic Food Product Technol 13: 47-53.

Adams M, Cooke R, Twiddy D. 1987. Fermentation parameters involved in the production of lactic acid preserved fish-glucose substrates. Int J Food Sci Technol 22: 105-114.

Agati V, Guyot JP, Morlon-guyot P, Tlamond P, Hounhouigan DJ. 1998. Isolation and characterization of new amylotitic strains of Lactobacillus fermentum from fermented maize doughs (mawè and ogi) from Benin. J Appl Microbiol 85: 512-520.

Ahmed F. 1991. Scombroid (histamine) fish poisoning, Committee on evaluation of the safety of fishery products. Washington, DC: National Academic Press, pp. 93-96.

Andrade M, Cordoba J, Sanchez B, Casado E, Rodriguez M. 2009. Evaluation and selection of yeasts isolated from dry-cured Iberian ham by their volatile compound production. Food Chem 113: 457463.

Anihouvi VB, Hounhouigan JD, Ayernor GS. 2005. La production et la commercialisation du Lanhouin, un condiment à base de poisson fermenté du Golfe du Bénin. Cah Agricult 14(3): 323330.

Anihouvi VB, Hounhouigan JD, Ayernor GS. 2006. Quality characteristics of Lanhouin: a traditionally processed fermented fish product in the republic of Benin. Afr J Food Agricult Nutr Dev 6 (1): $1-15$.

Anihouvi VB, Sakyi-Dawson E, Ayernor GS, Hounhouigan JD. 2007. Microbiological changes in naturally fermented cassava fish (Pseudotolithus sp.) for lanhouin production. Int J Food Microbiol 116: 287-291.

Anihouvi VB, Kindossi JM, Hounhouigan JD. 2012a. Processing and quality characteristics of some major fermented fish products from Africa: a critical review. Int Res J Biol Sci 1(7): 72-84.

Anihouvi VB, Kpoclou EY, Hounhouigan JD. 2012b. Use of starter cultures of Bacillus and Staphylococcus in the controlled fermentation of Lanhouin, a traditional fishbased condiment from West Africa, Afr J Microbiol Res 6: 4767-4774.

Anihouvi VB, Toudonou HJ, Akissoe NH, Hounhouigan JD. 2012c. Essai de mise au point d'un ferment pour la production artisanale du Lanhouin, un condiment à base de poisson fermenté au Bénin. Bull Recherche Agron Bénin (BRAB) 72; 11 p.

Anihouvi VB, Kindossi J, Hounhouigan J, Devillers J, Boucher MG, Doucet P. 2015. Guideline for the industry for lanhouin; Projet after, Deliverable 7.1.1.6; Guide technique, 18 p.

Annan N, Poll L, Sefa-Dedeh S, Plahar W, Jakobsen M. 2003. Volatile compounds produced by Lactobacillus fermentum, Saccharomyces cerevisiae and Candida krusei in single starter culture fermentations of Ghanaian maize dough. J Appl Microbiol 94: 462-474. Doi: 10.1046/J.1365-2672.2003.01852.

Anupam G, Kazufumi O, Toshiaki O. 2009. Extractive components and taste aspects of fermented fish pastes and bean pastes prepared using different koji molds as starters. Food Sci Technol 75: 481489.

Ba H. 2005. Les transformatrices de poissons à Pikine : le groupement économique féminin (GÉF) de Pencum Sénégal à Thiaroye-surmer. Cahiers du CRISES. Collection Études de cas d'entreprises d'économie sociale, $\mathrm{n}^{\circ}$ ES0503, 56 p.

Beddows C. 1985. Fermented fish and fish products. In: Wood B, ed. Microbiology of fermented foods. New York: Elsevier Applied Science Publishers, 2, pp. 44-55.

Bolumar T, Sanz Y, Flores M, Aristoy MC, Toldra F, Flores J. 2006. Sensory improvement of dry-fermented sausages by the addition of cell-free extracts from Debaryomyces hansenii and Lactobacillussakei. Meat Sci 72: 457-466.
Boudhrioua N, Djendoubi N, Bellagha S, Kechaou N. 2009. Study of moisture and salt transfers during salting of sardine fillets. $J$ Food Eng 94(1): 83-89.

Diop MB. 2008. Selection and characterisation of bacterial strains capable of enhancing the process of fish preservation by salting in Senegal, PhD Thesis, Gembloux Agricultural University, $213 \mathrm{p}$.

Diop MB, Dauphin R, Tine E, Ngom A, Destain J, Thonart P. 2007. Bacteriocin producers from traditional food products. Biotechnol Agron Soc Environ 11(4): 275-281.

Diop MB, Dubois-Dauphin R, Destain J, Tine E, Thonart P. 2009a. La conservation du poisson au Sénégal: utilisation d'une souche locale de Lactococcus lactis. Cah Agric 18(4): 337-342.

Diop MB, Dubois-Dauphin R, Destain J, Tine E, Thonart P. 2009b. Use of a Nisin-producing Starter Culture of Lactococcus lactis subsp. lactis to improve traditional fish fermentation in Senegal. $J$ Food Prot 72: 1930-1934.

Diop MB, Destain J, Tine E, Thonart P. 2010. Les produits de la mer au Sénégal et le potentiel des bactéries lactiques et des bactériocines pour la conservation. Base 14(2): 341-350.

Diop MB, Destain J, Alvarez VB, Konte MA, Thonart P. 2015. Use of nisin-producing starter cultures of Lactococcus lactis subsp. lactis on cereal based-matrix to optimize preservative factors over fish fermentation at $30^{\circ} \mathrm{C}$ typical to Senegal. J Food Process Technol 6: 432.

Diop MB, Alvarez VB, Guiro AT, Thonart P. 2016. Efficiency of neutralized antibacterial culture supernatant from bacteriocinogenic lactic acid bacteria supplemented with salt in control of microorganisms present in Senegalese artisanally handled fish by immersion preservative technology during guedj seafood processing at $10^{\circ} \mathrm{C}$ and $30^{\circ} \mathrm{C}$. J Food Microbiol Safety Hyg 1: 10. Doi: $10.4172 / 2476-2059$.

Dortu C. 2002. Isolement et caractérisation de souches de bactéries lactiques productrices de bactériocines dans les produits halieutiques fermentés au Sénégal, Mémoire de fin d'étude en vue de l'obtention du grade d'Ingénieur Chimiste et des Bio-industries.

Dossou-Yovo P. 2002. Biochemical justification for the improvement of the traditional methods of production of the lanhouin in Benin. Russia: Thesis submitted to the Krasnodar State Technological University, $129 \mathrm{p}$.

Dossou-Yovo P, Josse Roger G, Bokossa I, Palaguina I. 2011. Survey of the improvement of fish fermentation for lanhouin production in Benin. Afr J Food Sci 5(17): 878-883.

DPM (Direction de la pêche maritime). 2014. Résultats généraux de la pêche maritime sénégalaise. Rapports 2014. Dakar, Sénégal.

DPM (Direction de la pêche maritime). 2016. Résultats généraux de la pêche maritime sénégalaise. Rapports 2016. Dakar, Sénégal.

El Sheikha AF, Ray R, Montet D, Panda S, Worawattanamateekul W. 2013. African fermented fish products in scope of risks. Int Food Res $J$ 21(1): 425-432.

Enquête Cadre UEMOA (Union économique et monétaire Ouestafricaine), 2014. Atlas des pêches artisanales maritimes: projet d'appui aux statistiques des pêches. http://atlas.statpecheemoa.org/.

Essuman KM. 1992. Le poisson fermenté en Afrique: traitement, commercialisation et consommation. Doc. Tech. Pêches, 329. Rome: FAO, 86 p.

Eyo A. 1991. Studies on the preparation of fermented fish products from Alestes nurse. In: Proceedings of FAO expert consultation on fish technology in Africa. Ghana: Accra.

Fall NG, Tounkara LS, Diop MB, Thiaw OT, Thonart P. 2014. Étude socioéconomique et technologique de la production du poisson fermenté et séché (Guedj) au Sénégal. Int J Biol Chem Sci 8(6): 2523-2538. 
Fall NG, Tounkara LS, Diop MB, Thiaw OT, Thonart P. 2017. Chemical characteristics and microbial quality of Guedj a traditional fermented fish from Senegal. Int $J$ Sci 6(6): 48-54. DOI: $10.18483 /$ ijSci.1323.

FAO (Food Agriculture Organization). 1971. Fermented fish products, fisheries reports $\mathrm{n}^{\circ} 100$. Rome: FAO, $62 \mathrm{p}$.

FAO (Food Agriculture Organization). 2005. L'utilisation de la glace sur les bateaux de pêche artisanale. Documents techniques sur les pêches n ${ }^{\circ}$ 436. Rome: FAO, 118 p.

FAO (Food Agriculture Organization). 2014. La situation mondiale des pêches et de l'aquaculture. Possibilités et défis. Rome, 255 p.

Fatichenti F, Bergere JL, Deiana P, Farris GA. 1983. Antagonistic activity of Debaryomyces hansenii towards Clostridium tyrobutyricum and Clostridium butyricum. J Dairy Res 50: 449-457.

Fleet GH. 2007. Yeasts in foods and beverages: impact on product quality and safety. Curr Opin Biotech 18: 170-175.

Gallart-Jornet L, Barat JM, Rustad T, Erikson U, Escriche I, Fito P. 2007. A comparative study of brine saltin gof Atlantic cod (Gadus morhua) and Atlanticsalmon (Salmo salar). J Food Eng 79(1): 261-270.

Gomna A, Rana K. 2007. Inter-household and intra-household patterns of fish and meat consumption in fishing communities in two states in Nigeria. Br J Nutr 97: 145-152.

Gram L. 2003. Fermented fish products microbiology and technology. Retrieved February 13, from http://www.dfu.min.dk/micro/lg.htm.

Groupe de recherche et d'échanges technologiques (GRET) et Centre technique de coopération agricole et rurale (CTA). 1993. Conserver et transformer le poisson. Guide technique et méthodologique, Collection «Le point sur». Paris: GRET et Wageningen, CTA.

Halm M, Osei-Yaw A, Hayford A, Kpodo KA, Amoa-Awua WKA. 2004. Experiences with the use of a starter culture in the fermentation of maize for "kenkey" production in Ghana. World $J$ Microbiol Biotechnol 12(5): 531-536.

Hanson SW, Knowles MJ, Al-Kasadi AS. 1985. Histamine in Southeast Asia cured fish and changes in histamine levels during salting and drying. FAO Fisheries Report no. 317, Supplement, pp. 386-392.

Historique météo, 2018. Archives météo pour le monde. http://www. historique-météo.net Afrique (Google).

Holzapfel WH. 2002. Appropriate starter culture technologies for small-scale fermentation in developing countries. Int J Food Microbiol 75: 197-212.

Horner WFA. 1997. Preservation of fish by curing (drying, salting and smoking). In: Hall GM ed. Fish processing technology, 2nd ed. London: Blackie Academic \& Professional, 32 p.

Hounhouigan DJ, Nout MJR, Nago CM, Houben JH, Rombouts FM. 1999. Use of starter cultures of lactobacilli and yeast in the fermentation of mawè, an african maize product. Trop Sci 39: 220-226.

Jay JM, Loessner MJ, Golden DA. 2005. Modern food microbiology. Food Science Text Series. Boston, MA: Springer.

Jin-Jin J, Qing-Xiao Z, Zhi-Wei Z, Li-Yan Z. 2007. Chemical and sensory changes associated Yu-lu fermentation process - A traditional Chinese fish sauce. Food Chem 104: 1629-1634.

Kandler O. 1983. Carbohydrate metabolism in lactic acid bacteria. Antonie Van Leeuwenhoek 49(3): 209-224.

Kanner J, Harel S, Joffe R. 1991. Lipid peroxidation of muscle food as affected by NaCl. J Agric Food Chem 3: 1017-1024.

Kerr M, Lawicki P, Aguirre S, Rayner C. 2002. Effect of storage conditions on histamine formation in fresh and canned tuna. Werribee (Australia): State Chemistry Laboratory Department of Human Service, Food Safety Unit, Victorian Government, pp. 5-20.

Koffi-Nervy R, Ouina TST, Koussemon M, Brou K. 2011. Chemical composition and lactic microflora of adjuevan, a traditional Ivorian fermented fish condiment. Pakistan J Nutr 10(4): 332-337.
Koffi-Nevry R, Koussémon M. 2012. Microbiological composition, processing and consumer's characteristics of Adjuevan, a Traditional Ivorian Fermented Fish. Tropicultura 30(1): 9-14.

Kopermsub P, Yunchalard S. 2010. Identification of lactic acid bacteria associated with the production of plaasom, a traditional fermented fish product of Thailand. Int J Food Microbiol 138(3): 200-204.

Kostinek MS, Edward VA, Schillinger U, Hertel C, Holzapfel WH, Franz CMAP. 2005. Diversity and technological properties of predominant lactic acid bacteria from fermented cassava used for the preparation of Gari, a traditional African food. Syst Appl Microbiol 28: 527-540.

Kouakou AC, Cisse M, Kossonou E, Brou KD, Marcellin KD, Montet D. 2012a. Identification of yeasts associated with the fermented fish, adjuevan, of Ivory Coast by using the molecular technique of PCR-denaturing gradient gel electrophoresis (DGGE). Afr $J$ Microbiol Res 6(19): 4138-4145.

Kouakou AC, Kouadio FN, Dadier A, Thomas MKD, Montet D. 2012b. Application of culture dependent methods and cultureindependent methods (DGGE analysis) to study Lactic acid bacteria ecology of Ivorian fermented fish Adjuevan. Challenges Modern Technol 3(1): 51-56.

Kouakou AC, Kouadio FNG, Dadie AT, Montet D, Djè MK. 2013. Production et commercialisation de l'adjuevan, poisson fermenté de Côte d'Ivoire. Cah Agric 22: 559-567.

Lo M. 1993. Contribution à l'étude de la qualité microbiologique et chimique des poissons fermentés-séchés artisanaux Sénégalais: «le Guedj et le Tambadiang ». Dakar: Thèse de doctorat, Université Cheick Anta Diop, 87 p.

Lopandic K, Zelger S, Banszky LK, Eliskases-Lechner F, Prillinger H. 2006. Identification of yeasts associated with milk products using traditional and molecular techniques. Food Microbiol 23: 341-350.

Montel MC, Béranger C, Bonnemaire J. 2005. Les fermentations au service des produits de terroir (Broché). Editeur: Inra, Collection «le point sur», $312 \mathrm{p}$.

Martin A, Cordoba JJ, Aranda E, Cordoba MG, Asensio MA. 2006. Contribution of a selected fungal population to the volatile compounds on dry-cured ham. Int J Food Microbiol 110: 8-18.

Mauguin S, Novel G. 1994. Characterization of lactic acid bacteria isolated from seafood. J Appl Bacteriol 76: 616-625.

Nandhsha F, Soottawat B, Suttirug P, Wanwisa B. 2009. Chemical composition and antioxidative activity of Thai traditional fermented shrimp and krill products. J Food Chem 119: 133-140.

Nayeem MA, Pervi K, Reza MS, Khan MNA, Islam MN, Kamal M. 2010. Marketing System of traditional dried and semi-fermented fish product (cheap shutki) and socio-economic condition of the retailers in local market of Mynensingh region, Bangladesh. Bangladesh Res Publ J 4: 69-75.

Nerquaye-Tetteh GA, Eyeson KK, Tete-Marmon J. 1978. Studies on momone, a Ghanaian fermented fish product. Ghana J Agricult Sci 11: $21-26$.

Ndiaye O, Diei-Ouadi Y. 2009. De la pirogue à l'étal : équipements améliorés de manutention et de transformation pour la pêche artisanale. Document technique sur les pêches et l'aquaculture. $\mathrm{N}^{\circ}$ 535. Rome: FAO, $65 \mathrm{p}$.

Nout R, Joseph D, Tiny Van Boekel B. 2003. Les aliments: transformation, conservation et qualité. Publishers/ CTA 90-5782, pp. 124-129.

Oguntoyinbo FA. 2007. Identification and functional properties of dominant lactic acid bacteria isolated at different stages of solid state fermentation of cassava during traditional gari production. World J Microbiol Biotechnol 23: 1425-1432. 
Oksuz A, Evrendilek GA, Calis MS, Orezen A. 2008. Production of a dry sausage from African fish culture. J Aquacult Tropics 5: 87-90.

Olasupo NA, Olukoya DK, Odunfa SA. 1996. Studies on local strains of amylolytic Lactobacillus from Nigerian fermented foods. Narhung 40(S): 44-46.

Olsen SJ, Mackinon LC, Goulding JS, Bean NH, Slutsker L. 2000. Surveillance for foodborne-desease outbreaks-United States, 19931997. Morbidity Weekly report CDC. Surveill Summ 49: 1-62.

Ostergaard A, Ben Embark PK, Yamprayoon J, Wedell-Neergaard C, Huss HH, Gram L. 1998. Trop Sci 38: 105-112.

Oyewole OB. 1997. Lactic fermented foods in Africa and their benefits. Food Control 8: 289-297.

Palludan-Müller C, Madsen M, Sodphanodora P, Gram L, Lange Moller P. 2002. Fermentation and microflora of Plaa-som, a Thai fermented fish product prepared with different salt concentrations. Int J Food Microbiol 73: 61-70.

Palludan-Müller C, Madsen M, Sophanodora P, Gram L, Mommer PL. 2002a. Fermentation and microflora of plaa-som, a thai fermented fish product prepared with different salt concentrations. Int J Food Microbiol 73: 61-70.

Parkouda C, Nielsen D, Azokpota P, Ouoba L, AmoaAwua W, Thorsen L, et al. 2009. The microbiology of alkaline-fermentation of indigenous seeds used as food condiments in Africa and Asia. Crit Rev Microbiol 35: 139-156.

Pearson D. 1976. The chemical analysis of foods 7 th ed. Edinburgh London and New York: Churchill Livingstone, pp. 387-497.

Petrus Purnomo H, Suprayitno E, Hardoko. 2013. Physicochemical characteristics, sensory acceptability and microbial quality of Wadi Betok, a traditional fermented fish from South Kalimantan, Indonesia. Int Food Res $J$ 20(2): 933-939.

Riebroy S, Benjakul S, Visessanguan W. 2008. Properties and acceptability of Som-fug, a Thai fermented fish mince, inoculated with lactic acid bacteria starters. LWT-Food Sci Technol 41: 569-580.

Saisithi P, Yongmanitchai P, Chimanage P, Wongkhalaung C, Boonyaratanakornkit, Maleehuan S. 1986. Improvement of a Thai traditional fermented fish product: som-fug. Bangkok: Institute of Food Research and Product Development, Kasetsart University, FAO repport 1986.

Sanni AI, Morlon-guyot J, Guyot JP. 2002. New efficient amylaseproducing strains of Lactobacillus plantarum and L.fermentum isolated from different Nigerian traditional fermented foods. Int $J$ Food Microbiol 72: 53-62.

Sanni A, Asiedu M, Ayernor G. 2002. Microflora and chemical composition of momoni, a Ghanaian fermented fish condiment. $J$ Food Composition Anal 15: 577-583.

Sefa-Dedeh S, Youngs A. 1976. The bacteriological quality of Ghanaian solar salt with reference to its use in fish preservation. Ghana J Sci 16: 7-13.

Silva C, Da Ponte D, Dapkevicius M. 1998. Storage temperature effect on histamine formation in Big Eye Tuna and Shkipjack. $J$ Food Sci 63: 644-647.

Smita HP, Ramesh CR, Aly FES, Didier M, Wanchai W. 2011. Fermented and fish products: an overview. Aquacult Microbiol Biotechnol 2: 132-172.

Tanasupawat S, Namwong S, Kudo T, Itoh T. 2007. Piscibacillus salipiscarius gen, nov., a moderately halophilic bacterium from fermented fish (pla-ra) in Thailand. Int J Syst Evolution Microbiol 57: 1413-1417.

Troller JA, Christian JHB. 1978. Water activity and food. New York: Academics Press, pp. 9-11.

Tsai YH, Lin CY, Chang SC, Chien LT, Lee TM, Wei CI. 2006. Histamine contents of fermented fish products in Taiwan and isolation of histamine-forming bacteria. Food Chem 98: 64-70.

Vieira-Dalode G, Jespersen JL, Hounhouigan J, Moller PL, Nago CM, Jakobsen M. 2007. Lactic acid bacteria and yeasts associated with gowé production from sorghum in Benin. J Appl Microbiol 103: 342-349.

Yachai M, Tanasupawat S, Itoh T, Benjakul S, Visessanguan W, Valyasevi R, et al. 2008. From fermented fish (pla-ra) in Thailand. Int J Syst Evolution Microbiol 58: 2136-2140.

Yankah W. 1988. Studies on momone: a Ghanaian fermented fish product, in Department of Nutrition and Food Science. Legon: Ed. University of Ghana, $80 \mathrm{p}$.

Yao AA, Egounlety M, Kouame LP, Thonart P. 2009. Les bactéries lactiques dans les aliments ou boissons amylacés et fermentés de l'Afrique de l'Ouest: leur utilisation actuelle ; formation continuearticle de synthèse. Ann Med Vet 153: 54-65.

Zaman MZ, Bakar FA, Selamat J, Bakar J. 2010. Occurrence of biogenic amines and amines degrading bacteria in fish sauce. Czech J Food Sci 28(5): 440-449.

Cite this article as: Fall M, Diop MB, Montet D, Maiga AS, Guiro AT. 2019. Fermentation du poisson en Afrique de l'Ouest et défis sociétaux pour une amélioration qualitative des produits (adjuevan, guedj et lanhouin): revue de la littérature. Cah. Agric. $28: 7$. 